www.jmscr.igmpublication.org

Impact Factor (SJIF): 6.379

Index Copernicus Value: 79.54

ISSN (e)-2347-176x ISSN (p) 2455-0450

crossrefDOI: https://dx.doi.org/10.18535/jmscr/v6i11.145

Journal Of Medical Science And Clinical Research

IGM Publication

An Official Publication of IGM Publication

\title{
Clinical Profile and Long Term Outcome of NMDA Receptor Encephalitis- A Tertiary Care Centre Experience
}

\author{
Authors \\ Dr Dileep.R, Dr Benjamin Ramacha, Dr Praveen Panicker, Dr Thomas Iype \\ Department of Neurology, Government Medical College, Thiruvananthapuram, India
}

\begin{abstract}
Introduction: Anti-N-methyl-D-aspartate receptor (NMDAR) encephalitis is an autoimmune encephalitis which predominantly affects children and young adults especially females.

Aim: To study the clinical profile and long term outcome of the patients with Anti NMDA receptor antibody positive encephalitis and assess their response to treatment.

Materials and Methods: Patients admitted in our ward or ICU satisfying the criteria of possible autoimmune encephalitis with a cerebrospinal fluid NMDA Positivity were included. Data including the clinical features, cerebrospinal fluid findings, MRI brain findings, electroencephalography findings and treatment received was noted. All the patients had undergone screening for tumours especially ovarian teratoma. [USG/CT ABDOMEN/MRI ABDOMEN] .Follow up was done at six months and improvement was assessed at follow up.

Results: Mean age of our patients was 16 years and $91.7 \%$ of patients were females. Most common symptoms were behaviour changes and seizures.50 percentage of our patients went to a psychiatrist for initial consultation. CSF pleocytosis was seen in $83 \%$ of patients. MRI Brain was normal in $58 \%$ of patients. EEG slowing was seen in all patients. We could detect ovarian teratoma in $27.3 \%$ of female patients. Only two patients improved with steroids alone. Rest other patients required second line immunotherapy and rituximab. Majority of patients in our study improved without much sequel.

Conclusion: So a young female with new onset of behavioural symptoms, possibility of Autoimmune encephalitis should always be considered and investigated. Early identification and early initiation of treatment shows better response

Keyword: Anti-N-methyl-D-aspartate receptor (NMDAR) encephalitis.
\end{abstract}

\section{Introduction}

Anti-N-methyl-D-aspartate receptor (NMDAR) encephalitis is an autoimmune encephalitis known after $2007^{(1,2)}$. An UK study showed that among all case of encephalitis $4 \%$ of patients had antiNMDAR encephalitis ${ }^{(3)}$. Antibodies against the NR1 subunit of the NMDAR (NMDAR antibodies) produces this characteristic syndrome which affects children and young adults especially females.

Aim of our study was to study the clinical profile and long term outcome of the patients with Anti NMDA receptor antibody positive encephalitis and assess their response to treatment. 


\section{Methods}

Our study was a descriptive study which was conducted in department of Neurology, Government Medical College, Thiruvananthapuram after getting the approval from the human ethics committee .Patients admitted in our ward or ICU satisfying the criteria of possible autoimmune encephalitis with a Cerebrospinal fluid NMDA Positivity were included from January 2014 to January 2016(4).All other causes of encephalitis (like viral encephalitis) and encephalopathy were excluded.

Data including the clinical features, cerebrospinal fluid findings, MRI brain findings, electroencephalography (EEG) findings and treatment received was noted. Assay for anti NMDAR antibody was done using cell based assays.All the patients had undergone screening for tumours especially ovarian teratoma. [USG/CT ABDOMEN/MRI ABDOMEN].

Follow up was also recorded. Improvement was assessed with the modified Rankin scale (MRS) ${ }^{(5)}$. Patients will be labelled as having full recovery if they could go back to their normal life and job (MRS 0, normal cognition). Mild deficits was defined if they couldreturn to most activities of daily living and remained stable (MRS 1-2; mild cognitive dysfunction). Rest other cases were taken as severe deficits. Improvement was also assessed based on reduction in seizure frequency. Good Response was defined as reduction in seizure frequency to more than or equal to $50 \%$ of admission. Poor Response was defined as reduction in seizure frequency to less than $50 \%$ of admission. Improvement was also assessed based on symptom [extrapyramidal/speech disturbances] improvement $^{(6)}$.

\section{Results}

Twelve patients satisfied the criteria of autoimmune encephalitis with positive CSF anti NMDAR antibody. Mean age of presentation was 16 years. Majority of the patients were females (91.7\%,11 patients).
Most common symptoms were behaviour changes $(91.67 \%)$ and seizures $(83.3 \%)$.

Table 1- Symptoms of NMDARE

\begin{tabular}{|l|c|c|}
\hline Symptoms & $\begin{array}{c}\text { No of } \\
\text { patients }\end{array}$ & Percentage (\%) \\
\hline Behaviour changes & 11 & 91.67 \\
\hline Seizures & 10 & 83.3 \\
\hline Fever at onset & 9 & 75 \\
\hline Extrapyramidal & 7 & 58.3 \\
\hline $\begin{array}{l}\text { Decreased speech or } \\
\text { language disturbance }\end{array}$ & 2 & 16.7 \\
\hline Headache & 2 & 16.7 \\
\hline
\end{tabular}

Half the patients initially consulted a psychiatrist.

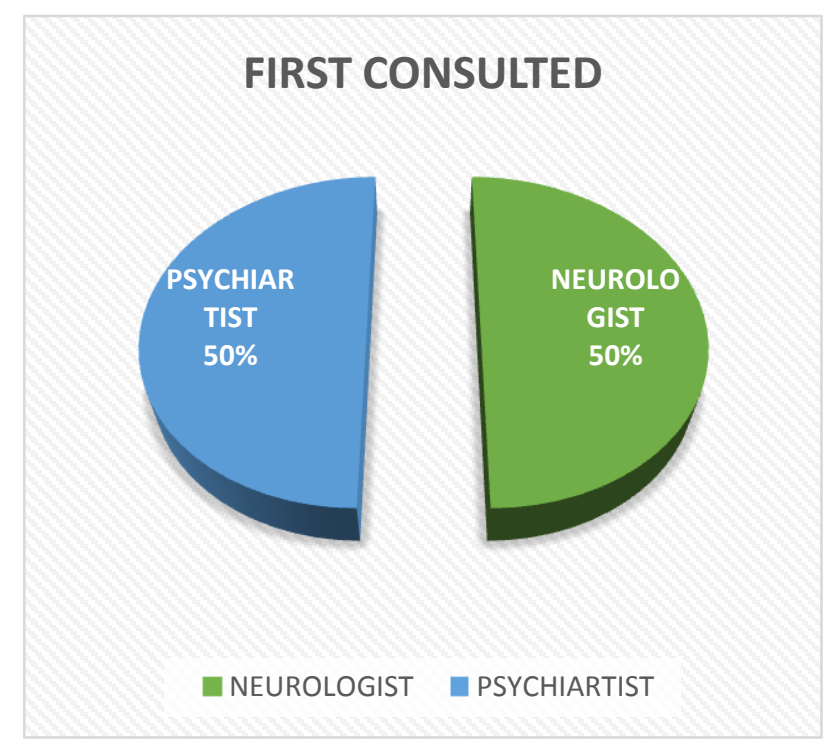

Figure 1 Pie diagram showed distribution of patient's first consultation

Most common Cerebrospinal fluid findings were lymphocytic pleocytosis (83.3\%) and increased protein $(66.7 \%)$.CSF was normal in two patients.

Table 2 Cerebrospinal fluid findings

\begin{tabular}{|l|c|c|}
\hline CSF Findings & $\begin{array}{c}\text { Number of } \\
\text { patients }\end{array}$ & $\begin{array}{c}\text { Percentage } \\
(\%)\end{array}$ \\
\hline CSF normal & 2 & 16.7 \\
\hline CSF Lymphocytic pleocytosis & 10 & 83.3 \\
\hline CSF protein elevated & 8 & 66.7 \\
\hline
\end{tabular}

MRI Brain was done in all patients. MRI was normal in seven patients (58.3\%).

Table 3 imaging findings

\begin{tabular}{|l|c|c|}
\hline MRI Brain finding & $\begin{array}{c}\text { Number } \\
\text { of patients }\end{array}$ & $\begin{array}{c}\text { Percentage } \\
(\%)\end{array}$ \\
\hline Normal & 7 & 58.3 \\
\hline Frontal T2W hyperintensities & 2 & 16.7 \\
\hline Occipital T2W hyperintensities & 2 & 16.7 \\
\hline $\begin{array}{l}\text { Mesial temporal T2W } \\
\text { hyperintensities }\end{array}$ & 1 & 8.3 \\
\hline
\end{tabular}


Electroencephalography (EEG) was abnormal in all patients. Background slowing was the most common findings. Inter epileptiform discharges were seen in frontal and occipital region in six patients.

Table 3 Electroencephalography (EEG) findings

\begin{tabular}{|l|c|c|}
\hline EEG Findings & $\begin{array}{c}\text { Number of } \\
\text { patients }\end{array}$ & $\begin{array}{c}\text { Percentage } \\
(\%)\end{array}$ \\
\hline $\begin{array}{l}\text { Generalised slowing(delta 1 } \\
\text { generalised) }\end{array}$ & 8 & 66.7 \\
\hline $\begin{array}{l}\text { Generalised slowing( delta } \\
2 \text { generalised) }\end{array}$ & 4 & 33.3 \\
\hline $\begin{array}{l}\text { Frontal inter epileptiform } \\
\text { discharges }\end{array}$ & 3 & 25 \\
\hline $\begin{array}{l}\text { Occipital inter epileptiform } \\
\text { discharges }\end{array}$ & 2 & 16.7 \\
\hline Delta brush & & \\
\hline
\end{tabular}

Imaging for malignancy was done in all patients. Patients underwent MRI or CT abdomen, pelvis and thorax. Ovarian teratoma was detected in three out of eleven $(27.3 \%)$ patients. Male patient did not have any malignancy.

All patients received one gram of methyl prednisolone intravenous for 5 days initially. In case of lack of improvement in one week, we started plasma exchange (2.5 litre of plasma per exchange for 5 exchanges) or Intravenous immunoglobulin followed by rituximab injection (500 mg IV injection 4 injections, one week apart).

Table 4- treatment given

\begin{tabular}{|l|c|c|}
\hline Treatment given & No of patients & Percentage (\%) \\
\hline Methyl prednisolone IV & 12 & 100 \\
\hline Plasma exchange & 10 & 83.3 \\
\hline Rituximab & 8 & 66.7 \\
\hline $\begin{array}{l}\text { Intravenous } \\
\text { immunoglobulin }\end{array}$ & 1 & 8.3 \\
\hline Teratoma surgery & 3 & 25 \\
\hline
\end{tabular}

All patients completed six month follow up. Regarding seizure control, all patients showed good response. Two patients who had language dysfunction improved completely. Mild Cognitive dysfunction (episodic memory) persisted in two patient.

Table 5- 6 month outcome of treatment

\begin{tabular}{|l|c|c|}
\hline $\begin{array}{l}\text { Outcome at 6 } \\
\text { months }\end{array}$ & No of patients & Percentage (\%) \\
\hline Full recovery & 10 & 83.3 \\
\hline Mild deficits & 2 & 16.7 \\
\hline severe deficits & 0 & 0 \\
\hline
\end{tabular}

\section{Discussion}

Mean age of our patients was 16 years which was slightly younger when compared to other studies. Josep Dalmau et al. study showed a mean age of 23 years $^{(1)} \cdot 91.7 \%$ of patients were females which was similar with other studies ${ }^{(1,7)}$ Most common symptoms were behaviour changes and seizures which was also similar to other studies ${ }^{(1,7)}$.

50 percentages of our patients went to a psychiatrist for initial consultation. In similar studies, $77 \%$ went for a psychiatry consultation first $^{(1)}$. CSF pleocytosis was seen in $83 \%$ of patients when compared with other studies where it was seen in $91 \%^{(1)}$. Pleocytosis was of lymphocytic predominant type.MRI Brain was normal in $58 \%$ of patients. Other studies showed a normal MRI in $33 \%{ }^{(7)}$ and $50 \%$. Normal MRI in an encephalitic patient cannot be used to rule out NMDAR encephalitis ${ }^{(8)}$.

EEG slowing was seen in all patients. In other studies, $71 \%^{(1)}$ and $90 \%{ }^{(7)}$ patients showed EEG slowing. We could detect ovarian teratoma in $27.3 \%$ of female patients which is lesser than other studies $^{(1)}$. Only two patients improved with steroids alone. Rest other patients required second line immunotherapy and rituximab. This is comparable to other studies where $92 \%$ were treated with first-line immunotherapy (steroid and Plasmapheresis/IVIg) and 27\% with second-line immunotherapy (Rituximab) ${ }^{(7)}$. Majority of patients in our study improved without much sequel. In in other studies, $85 \%$ patients were left with mild deficits ${ }^{(1)}$ and $78 \%$ patients achieved a good outcome ${ }^{(7)}$.

\section{Conclusion}

Anti-NMDAR encephalitis must be suspected in young patients with encephalitic syndrome with prominent neuro psychiatric symptoms and seizures. Early aggressive immunotherapy must be started in such a scenario. Tumour screening must be done in all patients.Early identification and early initiation of treatment shows better response 


\section{References}

1. Josep Dalmau MD, Amy J Gleichman BS, Ethan G Hughes BS, -David R Lynch MD. Anti-NMDA-receptor encephalitis: case series and analysis of the effects of antibodies. Lancet Neurology Volume 7, Issue 12, December 2008, Pages 10911098

2. Irani SR, Bera K, Waters P, et al. Nmethyl-Daspartate antibody encephalitis: temporal progression of clinical and paraclinical observations in a predominantly nonparaneoplastic disorder of both sexes. Brain 2010; 133: 1655-67.

3. Granerod J, Ambrose HE, Davies NW, et al. Causes of encephalitis and differences in their clinical presentations in England: a multicentre, population-based prospective study. Lancet Infect Dis. 2010

4. A clinical approach to diagnosis of autoimmune encephalitis. Graus, F., Titulaer, M. J., Balu, R., Benseler, S., Bien, C. G., Cellucci, T., Dalmau, J. The Lancet Neurology. 2016 Apr 1;15(4):391404

5. van Swieten JC, Koudstaal PJ, Visser MC, Schouten HJ, van Gijn J. Interobserver agreement for the assessment of handicap in stroke patients. Stroke 1988; 19: 604-7.

6. van Swieten JC, Koudstaal PJ, Visser MC, et al. Interobserver agreement for the assessment of handicap in stroke patients. Stroke. 1988;9:604-7.

7. Titulaer MJ, McCracken L, Gabilondo I, et al. Treatment and prognostic factors for long term outcome in patients with antiNMDA receptor encephalitis: an observational cohort study. Lancet Neurology 2013; 12: 157-65
8. Dalmau J, Lancaster E, MartinezHernandez E, Rosenfeld MR, BaliceGordon R. Clinical experience and laboratory investigations in patients with anti-NMDAR encephalitis. Lancet Neurol. 2011 Jan;10(1):63-74. 